\title{
Menstrual Variation in Experimental Pain: Correlation with Gonadal Hormones
}

\author{
M. Teepker ${ }^{a} \quad$ M. Peters ${ }^{b, c} \quad$ H. Vedder ${ }^{b, e} \quad$ K. Schepelmann ${ }^{a, d} \quad$ S. Lautenbacher ${ }^{c}$ \\ Departments of a Neurology and ${ }^{b}$ Psychiatry and Psychotherapy, Philipps University of Marburg, Marburg, \\ 'Department of Physiological Psychology, University of Bamberg, Bamberg, ${ }^{d}$ Schlei-Klinikum Schleswig MLK, \\ Schleswig, and ${ }^{\mathrm{e}}$ Psychiatrisches Zentrum Nordbaden, Wiesloch, Germany
}

\section{Key Words}

Gonadal hormones · Experimental pain · Pain threshold • Menstrual cycle

\begin{abstract}
Background: The results of studies examining the response to experimental pain during the menstrual cycle are conflicting because of differences in the definitions of the menstrual period, outcome measures and types of experimental pain stimulation. So far, there have been only a few studies correlating experimental pain with the levels of gonadal hormones over the menstrual cycle. Therefore, we assessed the responses to multiple experimental pain stimuli during the menstrual cycle and computed their correlations with the salivary concentrations of the gonadal hormones estrogen and testosterone. Methods: Twenty-four healthy and regularly menstruating women between 20 and 41 years old took part in the study. Detection thresholds (warmth, cold and electrical current) and pain thresholds (cold, heat, pressure and electrical current) were assessed on days 1, 4, 14 and 22 of the menstrual cycle. In each session, salivary samples were collected for the determination of the physiological estrogen $17 \beta$-estradiol, progesterone and testosterone. Progesterone was used exclusively to verify regular menstrual cycling. Results: Significant variations in pain thresholds for cold, pressure and electrical stimuli were observed over the
\end{abstract}

menstrual cycle with the highest thresholds on day 22, except for the cold pain thresholds, which peaked on day 14 . There were no such changes regarding heat pain and all the detection thresholds. The correlations separately computed for each of the 4 days between salivary estrogen as well as testosterone on the one hand and the detection or pain thresholds on the other hand failed to show significant levels, except for the coupling of testosterone and electrical pain thresholds on day 1. Conclusions: The pain thresholds for all the physical stressors increased after menstruation. The acrophases were located in the follicular (cold pain threshold) or in the luteal phase (pressure and electrical pain thresholds). The results of our correlation analyses indicate only minimal influences of the physiological levels of gonadal hormones on pain sensitivity in women.

Copyright $\odot 2010$ S. Karger AG, Basel

\section{Introduction}

Generally, the human menstrual cycle is divided into 3 phases: (1) the follicular phase (beginning with the onset of menstrual bleeding on day 1 and lasting for about 10-14 days); (2) the ovulatory phase (characterized by the rupture of the follicle from the ovary, approximately on day 14), and (3) the luteal phase (lasting 14 days from ovulation to the onset of menstrual bleeding). The follicular

\section{KARGER \\ Fax +4161306 1234 \\ E-Mail karger@karger.ch}

www.karger.com
(C) 2010 S. Karger AG, Basel

0302-282X/10/0613-0131\$26.00/0

Accessible online at:

www.karger.com/nps
Dr. Michael Teepker

Department of Neurology, Philipps University of Marburg

Rudolf-Bultmann-Strasse 8

DE-35039 Marburg (Germany)

Tel. +496421 58 65200, Fax +49 642158 65308, E-Mail teepker@ med.uni-marburg.de 
phase includes the menstrual period (days 1-4). Gonadal hormones such as estrogen and progesterone are responsible for the regulation of the menstrual cycle.

In some disorders such as temporomandibular pain disorder [1] or migraine $[2,3]$, pain varies across the menstrual cycle. In animal $[4,5]$ and human $[6,7]$ experimental studies, pain sensitivity has appeared to vary menstrually, too. The cyclic fluctuation of the female reproductive hormones estrogen and progesterone might explain these findings and, therefore, these hormones were targets for correlational research $[8,9]$. In animal studies, estrogen and progesterone were found to have an influence on nociception via the endogenous opioid system $[10-12]$. So far, little is known about the nociceptive effects of the male reproductive hormone testosterone during the menstrual cycle in females, although testosterone has been shown to reduce clinical pain in both men [13] and women [14]. Using the formalin test as a temporomandibular pain disorder model in the rat, Fischer et al. [15] demonstrated a significant attenuation of nociception by testosterone at supraphysiological serum levels.

Human experimental pain studies examining the cyclic variations in pain sensitivity were conducted by use of different types of physical stressors such as electrical, thermal or mechanical stimulation. Women showed higher thresholds for pressure pain, cold pressor pain, heat pain and ischemic muscle pain during the follicular phase. In contrast to this, experimental electrical pain was characterized by higher thresholds in the luteal phase [6]. However, the results were inconsistent as they varied depending on the outcome measures (pain intensity rating, pain threshold and pain tolerance threshold) and population characteristics (chronic pain patients and pain-free, normally cycling, women with or without use of oral contraceptives [7]).

The data based on human experimental pain are often limited by the small sample sizes and the lack of standardized operationalizations of the menstrual cycle. In particular, there has been no commonly accepted algorithm to identify the different menstrual phases, which is of critical relevance because the menstrual cycle varies inter- and intraindividually. Generally, pain perception has been quantified at different phases of the menstrual cycle, which have been chronologically determined and not verified by hormonal assessments. Such approaches have not controlled for irregular cyclic menstrual variations and have not been designed to assess the influence of gonadal hormones on pain responses.
There have been only a few studies trying to correlate the serum levels of estrogen and progesterone with experimental pain, i.e. ischemic pain [16], thermal pain [16, 17] and cold pressor pain [18] during different phases of the menstrual cycle. In 2 studies $[17,18]$, no significant correlations could be obtained. Fillingim et al. [16] described a significant correlation between estrogen and heat pain as higher estrogen levels were associated with lower heat pain and heat tolerance thresholds. However, this was not true for ischemic pain. Stening et al. [19] showed a significant correlation between gonadal hormones (i.e. estrogen and progesterone) and pain thresholds, too. Using the cold pressor test, pain sensitivity was increased during the late luteal phase and seemed to be dependent on the serum concentrations of progesterone in 16 females. Pain sensitivity was reduced when the serum levels of both estradiol and progesterone were high in parallel, suggesting joint influences of these hormones on pain sensation.

Since the method of experimental pain induction has appeared to be very critical, the first aim of the present study was to evaluate the cyclic variations in experimental pain in healthy volunteers, using various physical stressors. Experimental pain was induced by pressure, heat, cold and electrical stimulation on days 1, 4, 14 and 22 of the menstrual cycle because these time points characterize distinct phases in the physiological menstrual cycle: days 1 and 4 border the menstrual period within the follicular phase, on day 14 the rupture of the follicle naturally occurs (ovulatory phase), and day 22 marks the luteal phase. The second aim was to assess correlations between experimental pain and gonadal hormones on each day of testing because it is likely that the linkage itself varies over the menstrual cycle and overall correlations might be erroneous. The third aim of the present study was to consider the nociceptive role of testosterone besides estrogen. Progesterone was assessed only to verify the existence of regular menstrual cycles for each individual woman.

\section{Methods}

\section{Subjects}

Thirty-two healthy and pain-free women between 20 and 41 years (mean age $=27.3, \mathrm{SD}=6.1$ years) took part in the study. Menstrual cycles had to be regular $(28 \pm 1$ days $)$ as indicated by self-report. Subjects were recruited via wall posters and advertisements in local newspapers. In case of interest, they were examined both by a neurologist and a psychologist. The exclusion criteria were pregnancy, hypertension, acute and chronic pain, endocrine disorders, gynecological diseases, psychiatric disorders, periph- 
eral and central neuropathy, as well as dermatosis at the site of the pain stimulation. The Mini-DIPS (the German version of the Interview of Mental Disorders short version handbook [20]) was used to screen for psychiatric disorders. All the subjects did not take any drugs or oral contraceptives on a regular basis; furthermore, they were free of any analgesics and sedatives for at least the $24 \mathrm{~h}$ preceding each test session. The subjects were instructed being awake and not having exercised for at least $1 \mathrm{~h}$ prior to the investigation. They were paid for their participation and gave written informed consent before participating in the study. The experimental protocol was approved by the ethics committee of the medical school of the University of Marburg.

Among the 32 subjects included in the study, 1 quitted before the fourth session because of familial problems, and 7 participants were excluded from statistical analysis because their menstrual cycle could not be verified as regular by assessment of progesterone (for details see the chapter Verification of Menstrual Cycle by Salivary Hormones). Due to a malfunction of the thermal stimulator, 1 participant could not be measured by this device, thus the number of subjects examined for thermal detection and pain thresholds lessened from 24 to 23 .

\section{General Procedure}

After the initial screening for exclusion criteria, the experimental investigations (each of them run by 2 female investigators) took place in a sound-attenuated laboratory of the University of Marburg and lasted approximately $1.5 \mathrm{~h}$ each. The time of day for the investigation was kept constant for each single subject over the 4 sessions. The sessions were run on days $1,4,14$ and 22 ( \pm 1 day) of the menstrual cycle according to the self-reported usual cycle phase and length. The sessions started with the sampling of saliva for an assessment of estrogen, progesterone and testosterone. Thereafter, the subjects were carefully familiarized with the sensory tests. The thresholds were assessed using the method of limits, in the following order: thermal thresholds, pressure pain thresholds and electrical thresholds.

\section{Assessment of Detection and Pain Thresholds}

Thermal Detection and Pain Thresholds

Cold and heat stimuli were applied using a computer-controlled thermal stimulator (TSA 2001; Medoc Ltd., Ramat Yishai, Israel) with a Peltier thermode (contact area: $6 \mathrm{~cm}^{2}$ ). The thermode was attached to the left forearm.

Detection Thresholds for Warmth and Cold: Beginning at a temperature of $32^{\circ} \mathrm{C}$, the thermode temperature increased or decreased at a rate of $1{ }^{\circ} \mathrm{C} / \mathrm{s}$ until the subject felt the first change in temperature and responded by pressing a button. Thereupon, the temperature returned at a rate of $1{ }^{\circ} \mathrm{C} / \mathrm{s}$ to the baseline temperature $\left(32^{\circ} \mathrm{C}\right)$ and was held constant until the next trial. The interstimulus intervals were at minimum $5 \mathrm{~s}$.

Pain Thresholds for Heat and Cold: The temperature increased or decreased from a baseline of $32^{\circ} \mathrm{C}$ at a rate of $1.5^{\circ} \mathrm{C} / \mathrm{s}$ until the subject felt the stimulus to be slightly painful and responded by pressing a button. Thereupon, the temperature returned at a rate of $2{ }^{\circ} \mathrm{C} / \mathrm{s}$ to the baseline temperature. The interstimulus intervals were at minimum $10 \mathrm{~s}$. For safety reasons, the upper limit of the temperature was set to $52^{\circ} \mathrm{C}$ and the lower limit to $0^{\circ} \mathrm{C}$. For those subjects who did not respond within the safety limits, the pain thresholds were set to the maximum values allowed, which was necessary only in the case of cold pain thresholds.
Five trials for each threshold (warmth detection threshold, cold detection threshold, cold pain threshold and heat pain threshold) were conducted and averages of these 5 trials used as the measure of the 4 thermal thresholds.

Pressure Pain Threshold

A pressure algometer (Somedic Sales AB, Hörby, Sweden) was used to assess responses to painful mechanical pressure stimuli, which were applied to a surface area of $1 \mathrm{~cm}^{2}$ on the center of the left volar forearm. To avoid local sensitization, the probe was moved slightly after each trial. The pressure gauge displayed the stimulation rate as kilopascal per second $(\mathrm{kPa} / \mathrm{s})$, and the slope to be reached was defined as $10 \mathrm{kPa} / \mathrm{s}$. The investigator increased the pressure constantly while monitoring the display until the subject felt the stimulus to be slightly painful and responded by pressing a button. Four trials were conducted, and the average of the maximum-recorded scores over the last 3 trials was used as a measure of the pressure pain threshold.

Electrical Detection and Pain Thresholds

An electrostimulator (Erich Jäger GmbH \& Co. KG, Friedberg, Germany) delivered the stimuli to the right volar forearm. The skin was cleaned and abraded. Each stimulus consisted of a train of 15 monophasic square-wave pulses (pulse duration: $4 \mathrm{~ms}$ ) with a stimulus onset asynchrony of $10 \mathrm{~ms}$ (resulting repetition rate within train: $100.0 \mathrm{~Hz}$; resulting duration of each electrical stimulus: $144 \mathrm{~ms}$ ). Two bipolar electrodes with a surface area of 0.3 $\mathrm{cm}^{2}$ covered with a special cream (Abralyt 2000; FMS Falk Minow Services, Herrsching am Ammersee, Germany) were attached $2 \mathrm{~cm}$ from each other slightly to the left and to the right of the center of the right volar forearm. For the assessment of electrical detection and pain thresholds, the stimulation intensity increased in $0.15-\mathrm{mA}$ steps. The subjects indicated detection and pain thresholds verbally by rating each stimulus as leading to 'no sensation', 'no painful sensation' or 'painful sensation'. For safety reasons, the intensity of stimulation was limited to $10 \mathrm{~mA}$. The detection and pain thresholds were assessed in 4 trials. The average of the maximum scores over the last 3 trials was used as a measure of the detection and pain thresholds.

\section{Collecting Saliva and Measuring Hormones}

At the beginning of each session, salivary samples were collected to determine the levels of the physiological estrogen $17 \beta$ estradiol, progesterone and free active testosterone. The subjects were instructed not to smoke, not to eat and not to drink fruit juice $1 \mathrm{~h}$ before collecting saliva. The volunteers had to chew a tasteless swab of cotton for $45 \mathrm{~s}$, which was afterwards put into a plastic tube (Salivette; Sarstedt AG \& Co., Nürnbrecht, Germany), frozen directly and stored at $-20^{\circ} \mathrm{C}$. For further analysis, the samples were thawed and centrifuged for $10 \mathrm{~min}$ at 3,000 rpm to remove cellular debris. ELISA assays (DRG Instruments $\mathrm{GmbH}$, Marburg, Germany) (table 1) were used to determine the hormonal concentrations following the producer's instructions.

\section{Verification of Menstrual Cycle by Salivary Hormones}

The menstrual cycle and its regulation by the hormones estrogen and progesterone can vary inter- and intraindividually even in normally cycling women. As a further inclusion criterion, we therefore used the existence of the regular hormonal pattern for progesterone over the menstrual cycle, with very low levels in the 
Table 1. Performance characteristics of salivary ELISA assays of physiological estrogen $17 \beta$-estradiol, progesterone and free active testosterone

\begin{tabular}{llll}
\hline & $\begin{array}{l}17 \beta- \\
\text { estradiol }\end{array}$ & $\begin{array}{l}\text { Proges- } \\
\text { terone }\end{array}$ & $\begin{array}{l}\text { Testos- } \\
\text { terone }\end{array}$ \\
\hline $\begin{array}{l}\text { Intra-assay coefficient of } \\
\quad \text { variation, \% }\end{array}$ & $2.59-6.92$ & $4.7-7.6$ & $6.2-13.8$ \\
$\begin{array}{l}\text { Inter-assay coefficient of } \\
\quad \text { variation, \% }\end{array}$ & $\begin{array}{l}2.1-4.33 \\
0.389\end{array}$ & $\begin{array}{l}5.3-7.7 \\
\text { Lower detection level, pg/ml }\end{array}$ & $\begin{array}{l}5.5-9.6 \\
1.9\end{array}$ \\
\hline
\end{tabular}

Data from the user's manual by DRG Instruments $\mathrm{GmbH}$.

Table 2. Salivary concentrations of physiological estrogen $17 \beta$ estradiol, progesterone and testosterone during menstrual cycle

\begin{tabular}{lcclll}
\hline & $\begin{array}{l}\text { Day of men- Num- } \\
\text { strual cycle }\end{array}$ & $\begin{array}{l}\text { Min. } \\
\text { bg/ml }\end{array}$ & $\begin{array}{l}\text { Max. } \\
\text { pg/ml }\end{array}$ & $\begin{array}{l}\text { Mean } \pm \text { SD } \\
\text { pg/ml }\end{array}$ \\
\hline 17ß-estradiol & 1 & 24 & 4.78 & 28.44 & $13.73 \pm 6.35$ \\
& 4 & 24 & 5.09 & 24.86 & $13.83 \pm 5.85$ \\
& 14 & 24 & 4.06 & 30.64 & $13.37 \pm 5.47$ \\
& 22 & 24 & 6.18 & 33.41 & $16.31 \pm 7.39$ \\
\hline Testosterone & 1 & 24 & 20 & 320 & $160 \pm 80$ \\
& 4 & 24 & 50 & 370 & $190 \pm 90$ \\
& 14 & 24 & 60 & 530 & $210 \pm 100$ \\
& 22 & 24 & 90 & 420 & $220 \pm 80$ \\
\hline Progesterone & 1 & 24 & 90 & 3,910 & $1,500 \pm 1,420$ \\
& 4 & 24 & 170 & 4,020 & $1,680 \pm 1,520$ \\
& 14 & 24 & 230 & 4,040 & $1,660 \pm 1,500$ \\
& 22 & 24 & 240 & 4,000 & $1,770 \pm 1,600$ \\
\hline
\end{tabular}

menstrual/follicular phase and higher concentrations during the luteal period. Seven women dropped out because they did not fulfill this criterion. Since we used progesterone for the verification of a regular menstrual cycle and, by that, restricted its variance, we could not enter it into further advanced analyses.

\section{Statistics}

Descriptive data are given as means \pm SD. Physical units were degrees Celsius for thermal sensitivity, kilopascal for pressure pain and milliampere for electrical sensitivity. In addition, zstandardized values were calculated for each subject and each variable over the 4 sessions in order to assess and demonstrate the pattern of intraindividual differences in comparable units. Cases which did not show any intraindividual variations in a given variable over the 4 sessions were excluded from the further statistical evaluation of this variable, leading to varying numbers of subjects as shown in tables 2-4. Multivariate data analyses (MANOVA) for repeated measurements were conducted to assess the intraindi- vidual differences in hormone levels, pain and detection thresholds depending on the menstrual cycle. Adjusting degrees of freedom with Greenhouse-Geisser correction was necessary if sphericity could not be observed. In case of significant results, post hoc tests ( $\mathrm{t}$ tests using Bonferroni-corrected $\alpha$ ) were used.

Furthermore, the relationship between salivary levels of hormones on the one hand and detection or pain thresholds on the other hand were examined by separately computing Pearson correlation coefficients for days $1,4,14$ and 22 . Significance was assumed with $\alpha=0.05$

\section{Results}

Gonadal Hormones during Menstrual Cycle

A MANOVA revealed a statistical significance for changes in $17 \beta$-estradiol and testosterone over the menstrual cycle $(\mathrm{F}=2.354$; d.f. $=6 / 138 ; \mathrm{p}=0.034)$. ANOVA for both of the 2 hormones showed different time patterns. Whereas the salivary concentrations of $17 \beta$-estradiol did not vary significantly during the menstrual cycle (ANOVA: $\mathrm{F}=1.961$, d.f. $=3 / 69, \mathrm{p}=0.128$ ) (table 2; fig. 1a), for testosterone a statistically significant difference could be observed (ANOVA: $F=3.176$, d.f. $=3 / 69, \mathrm{p}=0.029$ ) with lower salivary concentrations on day 1 than on day 22 (Bonferroni's test: $\mathrm{p}=0.034$ ) (table 2; fig. 1b). The progesterone values increased in a cycle-dependent manner, with the lowest concentrations on day 1 and the highest concentrations on day 22 (table 2). As only women with this well-known menstrual pattern of progesterone were included (for details see the chapter Verification of Menstrual Cycle by Salivary Hormones in the Methods section), no further statistical evaluation was computed for progesterone.

\section{Detection Thresholds during Menstrual Cycle}

No significant changes in the detection thresholds could be found during the menstrual cycle (MANOVA: $\mathrm{F}=1.737$, d.f. $=9 / 180, \mathrm{p}=0.083)($ table $3 \mathrm{a})$.

\section{Pain Thresholds during Menstrual Cycle}

The pain thresholds as a whole varied significantly during the menstrual cycle (table 3b; fig. 2a-d) (MANOVA: $F=3.244$, d.f. $=12 / 168, p<0.000$ ). For heat pain, no significant menstrual change could be detected (ANOVA: $\mathrm{F}=2.569$, d.f. $=2.798 / 53.164$, $\mathrm{p}=0.063$ ). Concerning cold pain, the change was significant (ANOVA: $\mathrm{F}=5.463$, d.f. $=2.790 / 53.008, \mathrm{p}=0.002$ ) with the lowest pain thresholds on day 1 and highest thresholds on day 14 (Bonferroni's t test for the differences between the 2 days: $p=0.003$ ). In contrast to this, the significantly cy- 
Fig. 1. Z-standardized salivary concentrations (means $\pm \mathrm{SD}$ ) of the physiological estrogen $17 \beta$-estradiol (a) and testosterone (b) during the menstrual cycle.
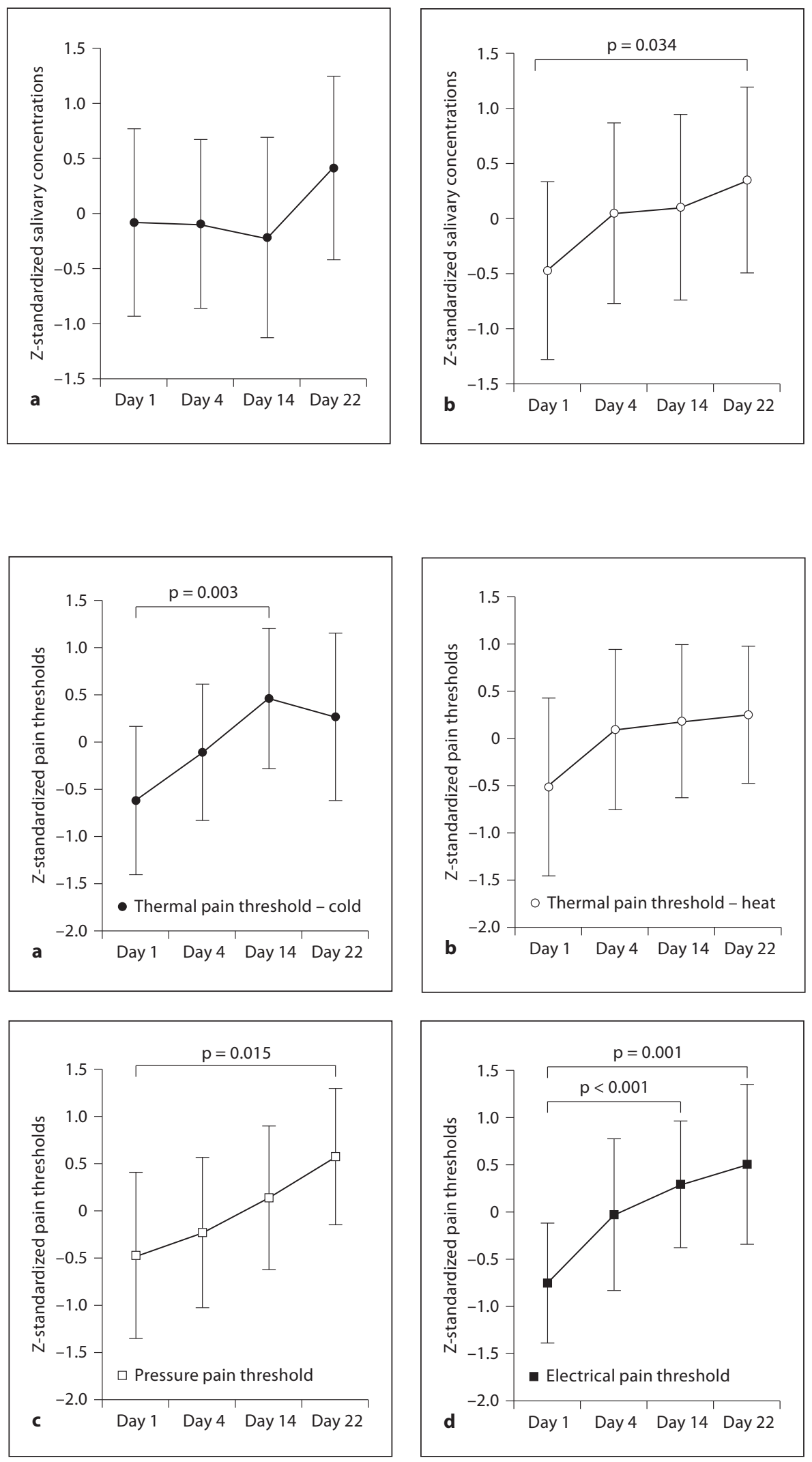

Fig. 2. Z-standardized experimental pain thresholds (means $\pm \mathrm{SD}$ ) during the menstrual cycle from day 1 to day 22. As thresholds for cold pain increase with declining temperature, we inverted the signs of the computed $\mathrm{z}$ values of the cold pain thresholds for comparable presentation. a Cold pain. b Heat pain. c Pressure pain. d Electrical pain. 
Table 3. Courses of thresholds during menstrual cycle

a Detection thresholds for cold, warmth and electrical current

\begin{tabular}{|c|c|c|c|c|}
\hline & Number & Min. & Max. & Mean \pm SD \\
\hline \multicolumn{5}{|c|}{ Thermal detection threshold - cold, ${ }^{\circ} \mathrm{C}$} \\
\hline Day 1 & 21 & -7.80 & -0.90 & $-2.82 \pm 2.26$ \\
\hline Day 4 & 21 & -8.50 & -0.90 & $-3.32 \pm 2.51$ \\
\hline Day 14 & 21 & -8.60 & -0.80 & $-3.72 \pm 2.03$ \\
\hline Day 22 & 21 & -7.00 & -0.90 & $-3.46 \pm 2.10$ \\
\hline \multicolumn{5}{|c|}{ Thermal detection threshold - warmth, ${ }^{\circ} \mathrm{C}$} \\
\hline Day 1 & 21 & 1.50 & 7.20 & $3.71 \pm 1.60$ \\
\hline Day 4 & 21 & 1.50 & 8.40 & $4.09 \pm 1.76$ \\
\hline Day 14 & 21 & 1.90 & 7.40 & $4.53 \pm 1.57$ \\
\hline Day 22 & 21 & 0.00 & 7.50 & $4.31 \pm 1.84$ \\
\hline \multicolumn{5}{|c|}{ Electrical detection threshold, mA } \\
\hline Day 1 & 21 & 0.40 & 0.75 & $0.52 \pm 0.11$ \\
\hline Day 4 & 21 & 0.30 & 0.85 & $0.56 \pm 0.16$ \\
\hline Day 14 & 21 & 0.30 & 0.75 & $0.50 \pm 0.15$ \\
\hline Day 22 & 21 & 0.30 & 0.75 & $0.52 \pm 0.14$ \\
\hline
\end{tabular}

b Pain thresholds for cold, heat, pressure and electrical current

\begin{tabular}{lcccr}
\hline & Number & Min. & Max. & Mean \pm SD \\
\hline Thermal pain threshold - cold, ${ }^{\circ} \mathrm{C}$ & & \\
Day 1 & 20 & 1.90 & 25.60 & $15.92 \pm 8.52$ \\
Day 4 & 20 & 0.00 & 25.30 & $12.15 \pm 8.72$ \\
Day 14 & 20 & 0.00 & 24.30 & $8.49 \pm 6.17$ \\
Day 22 & 20 & 0.00 & 20.40 & $8.85 \pm 7.11$ \\
\hline
\end{tabular}

Thermal pain threshold - heat, ${ }^{\circ} \mathrm{C}$

$\begin{array}{lllll}\text { Day 1 } & 20 & 42.90 & 48.80 & 46.08 \pm 1.38 \\ \text { Day 4 } & 20 & 42.50 & 49.60 & 46.54 \pm 1.87 \\ \text { Day 14 } & 20 & 43.40 & 49.60 & 46.68 \pm 1.75 \\ \text { Day 22 } & 20 & 43.40 & 49.80 & 46.73 \pm 1.69\end{array}$

\begin{tabular}{lcrrr}
\hline Pressure pain threshold, $\mathrm{kPa}$ & & & \\
Day 1 & 20 & 79.67 & 360.67 & $163.03 \pm 65.22$ \\
Day 4 & 20 & 74.00 & 341.33 & $176.10 \pm 62.99$ \\
Day 14 & 20 & 99.00 & 344.00 & $189.08 \pm 62.72$ \\
Day 22 & 20 & 108.33 & 337.67 & $200.50 \pm 58.65$
\end{tabular}

\begin{tabular}{lcccc}
\hline Electrical pain threshold, $\mathrm{mA}$ & & & \\
Day 1 & 20 & 1.00 & 6.45 & $2.76 \pm 1.50$ \\
Day 4 & 20 & 0.85 & 6.40 & $3.23 \pm 1.57$ \\
Day 14 & 20 & 1.15 & 7.00 & $3.53 \pm 1.64$ \\
Day 22 & 20 & 0.85 & 6.45 & $3.66 \pm 1.75$ \\
\hline
\end{tabular}

cling thresholds for pressure pain (ANOVA: $\mathrm{F}=5.036$, d.f. $=3 / 57, p=0.004)$ were increased on day 22 when compared with day 1 (Bonferroni's t test: $\mathrm{p}=0.015$ ). The data on electrical pain thresholds revealed a significant menstrual change (ANOVA: $\mathrm{F}=8.306$, d.f. $=2.386 / 45.328$, $\mathrm{p}<0.001$ ), with the lowest levels on day 1 and signifi- cantly higher values on day 14 (Bonferroni's $\mathrm{t}$ test: $\mathrm{p}<$ 0.001 ) and day 22 (Bonferroni's t test: $\mathrm{p}=0.001$ ).

\section{Correlation of Detection and Pain Thresholds with Gonadal Hormones}

The correlations of the detection and pain thresholds on the one hand with the gonadal hormones (i.e. 17 $\beta$ estradiol and testosterone) on the other hand, separately computed for days 1, 4, 14 and 22 of the menstrual cycle, are shown in tables $4 \mathrm{a}$ and $\mathrm{b}$. There was a statistically significant positive correlation $(\mathrm{r}=0.43)$ between salivary testosterone and electrical pain thresholds on day 1 of the menstrual cycle $(\mathrm{p}=0.04)$. The correlation between testosterone and heat pain thresholds on day 14 revealed near-significant results $(r=0.39 ; p=0.06)$. All other combinations of sensory thresholds and gonadal hormones did not result in significant correlations at any day of the menstrual cycle.

\section{Discussion}

First, this study aimed at examining the effects of the menstrual cycle on pain sensitivity, assessed by using multiple physical stressors to induce experimental pain, because earlier findings appeared to be strongly dependent on the physical type of pain induction. For all the induction techniques (warmth, cold, electrical current and pressure), the detection thresholds (here no pressure was applied) did not vary significantly, but the pain thresholds increased during the menstrual cycle from day 1 to day 22 (pressure and electrical current) or to day 14 (cold), with the exception of the heat pain threshold. Second, the attempt was made to separately correlate sensory thresholds with the salivary concentrations of gonadal hormones (estrogen and testosterone) on each day of testing during the menstrual cycle. There was merely 1 statistically significant correlation between testosterone and electrical pain thresholds on day 1 , whereas the 55 further attempts at finding significant associations between sensory thresholds and gonadal hormones failed. This happened although we included only women with regular menstrual cycles verified by the well-known changes in progesterone. We discuss our findings in this order.

The thresholds for cold pain revealed their highest levels on day 14 and their lowest levels on day 1 (menstrual/ follicular period) (fig. 2a). This is in contrast to the findings of Veith et al. [21] and Hapidou and de Catanzaro [22] demonstrating higher thresholds and tolerance dur- 
Table 4. Pearson correlations of physiological estrogen $17 \beta$-estradiol and testosterone during menstrual cycle

a Correlations with detection thresholds

\begin{tabular}{|c|c|c|c|}
\hline & $\mathrm{r}$ & $\mathrm{p}$ & Number \\
\hline \multicolumn{4}{|c|}{$17 \beta$-estradiol versus thermal detection threshold - cold } \\
\hline Day 1 & 0.10 & 0.97 & 23 \\
\hline Day 4 & 0.35 & 0.10 & 23 \\
\hline Day 14 & 0.22 & 0.92 & 23 \\
\hline Day 22 & 0.14 & 0.52 & 23 \\
\hline \multicolumn{4}{|c|}{$17 \beta$-estradiol versus thermal detection threshold - warmth } \\
\hline Day 1 & -0.13 & 0.57 & 23 \\
\hline Day 4 & -0.12 & 0.60 & 23 \\
\hline Day 14 & -0.23 & 0.30 & 23 \\
\hline Day 22 & -0.34 & 0.87 & 23 \\
\hline \multicolumn{4}{|c|}{$17 \beta$-estradiol versus electrical detection threshold } \\
\hline Day 1 & 0.28 & 0.19 & 24 \\
\hline Day 4 & -0.07 & 0.75 & 24 \\
\hline Day 14 & 0.19 & 0.41 & 22 \\
\hline Day 22 & 0.16 & 0.48 & 22 \\
\hline \multicolumn{4}{|c|}{ Testosterone versus thermal detection threshold - cold } \\
\hline Day 1 & 0.38 & 0.86 & 23 \\
\hline Day 4 & 0.56 & 0.80 & 23 \\
\hline Day 14 & 0.12 & 0.58 & 23 \\
\hline Day 22 & -0.29 & 0.18 & 23 \\
\hline \multicolumn{4}{|c|}{ Testosterone versus thermal detection threshold - heat } \\
\hline Day 1 & 0.26 & 0.24 & 23 \\
\hline Day 4 & -0.06 & 0.80 & 23 \\
\hline Day 14 & -0.18 & 0.42 & 23 \\
\hline Day 22 & -0.07 & 0.74 & 23 \\
\hline \multicolumn{4}{|c|}{ Testosterone versus electrical detection threshold } \\
\hline Day 1 & 0.29 & 0.17 & 24 \\
\hline Day 4 & -0.03 & 0.91 & 24 \\
\hline Day 14 & -0.30 & 0.18 & 22 \\
\hline Day 22 & 0.00 & 0.99 & 22 \\
\hline
\end{tabular}

ing the follicular period. Furthermore, Kowalczyk et al. [18] found no significant changes in cold pain thresholds or pain tolerance during the menstrual cycle.

Concerning heat pain sensitivity, the data from the literature have been conflicting, too. Whereas Fillingim et al. [16] demonstrated the highest heat thresholds during the follicular period, other data showed higher levels during the ovulatory phase $[23,24]$. Many studies in which heat pain stimuli were used found no significant effects [7], which is in line with our results (fig. 2b).

Riley et al. [6] concluded from their meta-analysis that pressure stimulation leads to higher thresholds in the follicular phase. In contrast to this, Sherman and LeResche [7], reviewing further studies on this topic, classified the b Correlations with pain thresholds

\begin{tabular}{cccc}
\hline & $\mathrm{r}$ & $\mathrm{p}$ & Number \\
\hline 17ß-estradiol versus & thermal & pain & thresholds - cold \\
Day 1 & 0.22 & 0.32 & 23 \\
Day 4 & 0.12 & 0.60 & 23 \\
Day 14 & 0.06 & 0.77 & 23 \\
Day 22 & -0.12 & 0.58 & 23
\end{tabular}

$17 \beta$-estradiol versus thermal pain thresholds - warmth

$\begin{array}{lrll}\text { Day } 1 & 0.14 & 0.54 & 23 \\ \text { Day } 4 & 0.23 & 0.29 & 23 \\ \text { Day } 14 & -0.32 & 0.14 & 23 \\ \text { Day 22 } & 0.14 & 0.53 & 23\end{array}$

$17 \beta$-estradiol versus pressure pain thresholds

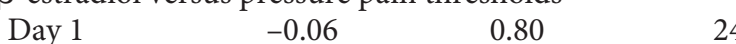

$\begin{array}{llll}\text { Day } 4 & 0.00 & 0.97 & 24\end{array}$

$\begin{array}{llll}\text { Day } 14 & 0.22 & 0.29 & 24\end{array}$

$\begin{array}{llll}\text { Day } 22 & 0.10 & 0.66 & 23\end{array}$

$17 \beta$-estradiol versus electrical pain thresholds

$\begin{array}{llll}\text { Day } 1 & 0.08 & 0.72 & 24\end{array}$

$\begin{array}{llll}\text { Day } 4 & -0.24 & 0.26 & 24\end{array}$

$\begin{array}{llll}\text { Day } 14 & 0.13 & 0.58 & 22\end{array}$

$\begin{array}{llll}\text { Day } 22 & 0.60 & 0.79 & 22\end{array}$

Testosterone versus thermal pain thresholds - cold

$\begin{array}{lrll}\text { Day } 1 & -0.17 & 0.44 & 23 \\ \text { Day } 4 & -0.03 & 0.90 & 23 \\ \text { Day } 14 & 0.20 & 0.35 & 23 \\ \text { Day 22 } & -0.31 & 0.15 & 23\end{array}$

Testosterone versus thermal pain thresholds - heat

$\begin{array}{lrrr}\text { Day } 1 & 0.12 & 0.59 & 23 \\ \text { Day } 4 & 0.09 & 0.68 & 23 \\ \text { Day 14 } & 0.39 & 0.06 & 23 \\ \text { Day 22 } & -0.18 & 0.41 & 23\end{array}$

\begin{tabular}{|c|c|c|c|}
\hline \multicolumn{4}{|c|}{ Testosterone versus pressure pain thresholds } \\
\hline Day 1 & 0.13 & 0.54 & 24 \\
\hline Day 4 & -0.03 & 0.90 & 24 \\
\hline Day 14 & -0.7 & 0.74 & 24 \\
\hline Day 22 & -0.18 & 0.41 & 23 \\
\hline \multicolumn{4}{|c|}{ Testosterone versus electrical pain thresholds } \\
\hline Day 1 & 0.43 & 0.04 & 24 \\
\hline Day 4 & 0.25 & 0.25 & 24 \\
\hline Day 14 & -0.22 & 0.32 & 22 \\
\hline Day 22 & -0.16 & 0.47 & 22 \\
\hline
\end{tabular}

results of pressure pain experiments to be contradictory with the highest pressure pain ratings probably between day 7 and day 21 of the menstrual cycle, indicating decreased pain thresholds during this time period. In our study, the thresholds for pressure pain varied significant- 
ly during the menstrual cycle, with the highest levels on day 22 (luteal phase) and the lowest levels on day 1 (menstrual/follicular phase) (fig. 2c).

Several studies on electrical pain indicated that highest thresholds are likely to be found in the luteal phase $[21,25]$. The results of these studies were - in contrast to experiments using other pain stimuli - well reproducible. In line with these data, we could find highest electrical pain thresholds during the luteal phase, too. The lowest thresholds were seen in the follicular phase (fig. 2d).

To summarize, the review of the literature suggests controversial results, especially with respect to thermal pain, as discussed above. Furthermore, menstrual effects have often been weak $[6,7]$. In this situation, we were able to demonstrate a rather homogenous pattern of responses to all physical forms of inducing experimental pain, with significantly increasing pain thresholds from day 1 to day 22 (pressure and electrical current) or to day 14 (cold) during the menstrual cycle except for heat pain. In line with earlier findings, we observed the greatest effects for electrical pain.

Alternative explanations of our findings not relating to menstrual cycle effects may exist. As our experiments always started on day 1 of the menstrual cycle and were afterwards run in the same chronological order, it is possible that the increasing pain thresholds were due to adaptation during repeated threshold assessments. However, most of the studies have not made use of randomized or balanced orders of menstrual cycle phases $[18,21]$. Giamberardino et al. [26] assessed pain thresholds for the electrical stimulation of the skin, subcutis and muscle tissue over the menstrual cycle and randomized the first phase of testing. In line with our results, they reported increasing thresholds for electrical pain stimuli from the follicular (days 2-6) to the luteal phase (days 17-22), too.

Concerning the correlations between the salivary levels of estrogen or testosterone and sensory thresholds, we failed to show significant results for almost all the possible combinations over the menstrual cycle. So far, only a few studies have tried to correlate the concentrations of gonadal hormones with the results of experimentally induced pain. The results have been conflicting: using the cold pressor test in normally menstruating women, Stening et al. [19] reported a significant and positive correlation between progesterone and lowered pain thresholds. Furthermore, increased pain intensity was associated with high progesterone levels and was found to be reduced by parallel increases in both estradiol and progesterone. Fillingim et al. [16] examined thermal and ischemic pain during 3 different phases of the menstrual cycle in 11 healthy women. They described an association between higher estrogen levels and increased thermal pain sensitivity but not ischemic pain responses. They concluded that a possible relationship between gonadal hormones and responses to experimental pain did not seem to be simply linear. Söderberg et al. [17] found no association between estradiol or progesterone and temperature pain thresholds determined by quantitative sensory testing in 19 healthy women at 3 time points during the menstrual cycle. Kowalczyk et al. [18] failed to show significant correlations between the gonadal hormones estradiol and progesterone and the responses to cold pressor pain in normally menstruating women, in women with an intake of oral contraceptives and in men. Accordingly, our not significant results regarding the correlations between gonadal hormones and detection or pain thresholds are in line with the data shown in the literature and suggest that pain processing is at best weakly related to gonadal hormones in healthy women. In our study, there was only 1 significant correlation, i.e. between testosterone and electrical pain thresholds on day 1 (menstrual phase). If this was not a mere chance finding, it might indicate that testosterone affects pain thresholds in healthy women, in a fashion which is dependent on the time during the menstrual cycle and on the pain induction technique. This finding might agree with clinical observations that chronic pain diseases such as fibromyalgia [14] or rheumatoid arthritis $[27,28]$ are associated with low androgen levels. Testosterone might influence pain by ameliorating chronic inflammatory processes [29] or via the opioid system [9]. Of note, testosterone can be physiologically aromatized into estrogen, and thus the effects of testosterone on nociception might be mediated through estrogen. Interestingly, in the majority of studies about the time course of testosterone, cyclic variation could be demonstrated in healthy women [30]. In spite of these observations, the function of testosterone in pain processing in women has not yet been established.

In contrast to our approach using saliva for hormonal assessment, serum was taken in most of the studies described above. Studies on the correlation between saliva and serum indicate that saliva sampling allows determining steroid hormones reliably [31]. Since collecting saliva is not as stressful as venipuncture, perturbing influences on pain experiments can be minimized. Concerning the missing cyclic variation in estrogen in our study, an explanation might be that concentrations of gonadal hormones are much lower in saliva than in serum, which 
might have reduced the reliability of our approach and, by that, might have required a more sensitive assay for hormonal determination. In contrast, the time course of testosterone is in line with cyclic variations reported earlier [30]. Nevertheless, we have to acknowledge as a further limitation that we collected saliva in Salivette tubes with cotton swabs. Dabbs [32] found unusually high salivary testosterone concentrations using these plastic tubes.

For their inclusion into the study, subjects had to report regular menstrual cycles ( $28 \pm 1$ days). Furthermore, regular menstrual cycling was verified by the analysis of progesterone and, according to our knowledge, used for the first time as a further criterion for inclusion into a study on menstrual variation in pain. Only women with increased progesterone levels on day 22 were kept in the study. It is admitted that the peak of progesterone might have been before or after day 22. However, it is very likely that in women with increased levels at this time the menstrual pattern of progesterone was regular.
Taken together, we could demonstrate that thresholds for physically different pain stimuli vary significantly during the menstrual cycle in healthy and normally menstruating women, showing a homogenous response pattern with increasing thresholds from day 1 to day 14 or to day 22. We were not able to show significant correlations between the salivary concentrations of gonadal hormones and detection or pain thresholds, except for testosterone and electrical pain thresholds on day 1 of the menstrual cycle. This negative finding of our correlation analysis indicates that pain processing is at best weakly regulated by gonadal hormones in women, or that the regulation occurs in a more complex and nonlinear fashion.

\section{Acknowledgment}

The study was supported by grants from the Dr. Robert Pfleger-Stiftung, Bamberg, Germany.

\section{References}

1 LeResche L, Mancl L, Sherman JJ, Gandara B, Dworkin SF: Changes in temporomandibular pain and other symptoms across the menstrual cycle. Pain 2003;106:253-261.

-2 Silberstein SD, Merriam GR: Estrogens, progestins, and headache. Neurology 1991;41: 786-793.

-3 Silberstein SD, Merriam GR: Sex hormones and headache. J Pain Symptom Manage 1993;8:98-114.

-4 Frye CA, Cuevas CA, Kanarek RB: Diet and estrous cycle influence pain sensitivity in rats. Pharmacol Biochem Behav 1993;45: 255-260.

-5 Kayser V, Berkley KJ, Keita H, Gautron M, Guilbaud G: Estrous and sex variations in vocalization thresholds to hindpaw and tail pressure stimulation in the rat. Brain Res 1996;742:352-354.

-6 Riley JL 3rd, Robinson ME, Wise EA, Price DD: A meta-analytic review of pain perception across the menstrual cycle. Pain 1999; $81: 225-235$

7 Sherman JJ, LeResche L: Does experimental pain response vary across the menstrual cycle? A methodological review. Am J Physiol Regul Integr Comp Physiol 2006;291:R245R256.

$\checkmark 8$ Aloisi AM: Gonadal hormones and sex differences in pain reactivity. Clin J Pain 2003; 19:168-174
9 Craft RM, Mogil JS, Aloisi AM: Sex differences in pain and analgesia: the role of gonadal hormones. Eur J Pain 2004;8:397411.

10 Dawson-Basoa M, Gintzler AR: Gestational and ovarian sex steroid antinociception: synergy between spinal kappa and delta opioid systems. Brain Res 1998;794:61-67.

-11 Bradshaw H, Miller J, Ling Q, Malsnee K, Ruda MA: Sex differences and phases of the estrous cycle alter the response of spinal cord dynorphin neurons to peripheral inflammation and hyperalgesia. Pain 2000;85:93-99.

-12 Kuba T, Wu HB, Nazarian A, Festa ED, Barr GA, Jenab S, Inturrisi CE, Quinones-Jenab $\mathrm{V}$ : Estradiol and progesterone differentially regulate formalin-induced nociception in ovariectomized female rats. Horm Behav 2006;49:441-449.

13 English KM, Steeds RP, Jones TH, Diver MJ, Channer KS: Low-dose transdermal testosterone therapy improves angina threshold in men with chronic stable angina: a randomized, double-blind, placebo-controlled study. Circulation 2000;102:1906-1911.

14 Dessein PH, Shipton EA, Joffe BI, Hadebe DP, Stanwix AE, van der Merwe BA: Hyposecretion of adrenal androgens and the relation of serum adrenal steroids, serotonin and insulin-like growth factor-1 to clinical features in women with fibromyalgia. Pain 1999;83:313-319.
15 Fischer L, Clemente JT, Tambeli $\mathrm{CH}$ : The protective role of testosterone in the development of temporomandibular joint pain. J Pain 2007;8:437-442.

16 Fillingim RB, Maixner W, Girdler SS, Light KC, Harris MB, Sheps DS, Mason GA: Ischemic but not thermal pain sensitivity varies across the menstrual cycle. Psychosom Med 1997;59:512-520.

17 Söderberg K, Sundström Poromaa I, Nyberg S, Bäckström T, Nordh E: Psychophysically determined thresholds for thermal perception and pain perception in healthy women across the menstrual cycle. Clin J Pain 2006; 22:610-616.

18 Kowalczyk WJ, Evans SM, Bisaga AM, Sullivan MA, Comer SD: Sex differences and hormonal influences on response to cold pressor pain in humans. J Pain 2006; 7:151160.

19 Stening K, Eriksson O, Wahren L, Berg G, Hammar M, Blomqvist A: Pain sensations to the cold pressor test in normally menstruating women: comparison with men and relation to menstrual phase and serum sex steroid levels. Am J Physiol Regul Integr Comp Physiol 2007;293:R1711-R1716.

20 Margraf J: Mini-DIPS: Diagnostisches KurzInterview bei psychischen Störungen. Berlin, Springer, 1994. 
-21 Veith JL, Anderson J, Slade SA, Thompson P, Laugel GR, Getzlaf S: Plasma beta-endorphin, pain thresholds and anxiety levels across the human menstrual cycle. Physiol Behav 1984;32:31-34.

-22 Hapidou EG, de Catanzaro D: Sensitivity to cold pressor pain in dysmenorrheic and nondysmenorrheic women as a function of menstrual cycle phase. Pain 1988;34:277-283.

-23 Goolkasian P: Cyclic changes in pain perception: an ROC analysis. Percept Psychophys 1980;27:499-504.

24 Goolkasian P: An ROC analysis of pain reactions in dysmenorrheic and nondysmenorrheic women. Percept Psychophys 1983;34: 381-386.
25 Tedford WH, Warren DE, Flynn WE: Alteration of shock aversion thresholds during the menstrual cycle. Percept Psychophys 1977; 21:193-196.

-26 Giamberardino MA, Berkley KJ, Iezzi S, de Bigontina P, Vecchiet L: Pain threshold variations in somatic wall tissues as a function of menstrual cycle, segmental site and tissue depth in non-dysmenorrheic women, dysmenorrheic women and men. Pain 1997;71: 187-197.

27 Cutolo M, Giusti M, Foppiani L, Seriolo B Briata M, Bisso A, Faelli F, Felli L, Prete C, Pizzorni C, Sulli A: The hypothalamic-pituitary-adrenocortical and gonadal axis function in rheumatoid arthritis. Z Rheumatol 2000;59(suppl 2):II65-II69.
28 Navarro MA, Nolla JM, Machuca MI, González A, Mateo L, Bonnin RM, Roig-Escofet D: Salivary testosterone in postmenopausal women with rheumatoid arthritis. J Rheumatol 1998;25:1059-1062.

29 Green PG, Dahlqvist SR, Isenberg WM, Strausbaugh HJ, Miao FJ, Levine JD: Sex steroid regulation of the inflammatory response: sympathoadrenal dependence in the female rat. J Neurosci 1999;19:4082-4089.

$>30$ Davison SL, Bell R: Androgen physiology. Semin Reprod Med 2006;24:71-77.

-31 Hofman LF: Human saliva as a diagnostic specimen. J Nutr 2001;131:1621S-1625S

>32 Dabbs JM Jr: Salivary testosterone measurements: collecting, storing, and mailing saliva samples. Physiol Behav 1991;49:815-817. 